\title{
Diapausing larvae of the midge Aphidoletes aphidimyza (Diptera: Cecidomyiidae) survive at subzero temperatures in a supercooled state but tolerate freezing if inoculated by external ice
}

\author{
VLADIMÍR KOŠŤÁL and JAN HAVELKA \\ Institute of Entomology, Academy of Sciences of the Czech Republic, Branišovská 31, 37005 České Budějovice, Czech Republic; \\ e-mail: kostal@entu.cas.cz
}

Key words. Aphidoletes aphidimyza, Cecidomyiidae, Diptera, diapause, cold hardiness, supercooling, freezing, survival

\begin{abstract}
Diapausing larvae of Aphidoletes aphidimyza (Diptera: Cecidomyiidae) had relatively low supercooling points (SCP) ranging from -19.0 to $-26.4^{\circ} \mathrm{C}$. None of the specimens that froze at this temperature survived. A high survival rate (up to $87 \%$ ) at $-10^{\circ} \mathrm{C}$ for 10 days was observed in supercooled larvae. Such features are characteristic for insects that use a chill-tolerance strategy of cold hardiness. However, the cocoons formed by the diapausing larvae were penetrable by external ice crystals and the larvae showed a relatively high survival rate $(23-34 \%)$ at $-10^{\circ} \mathrm{C}$ for 10 days also in the frozen state caused by inoculation by external ice at high subzero temperatures. Such a duality with respect to cold hardiness strategies seems to be ecologically relevant to overwintering in soil habitats where there may be unpredictable contact with external ice.
\end{abstract}

\section{INTRODUCTION}

The overwintering strategies of insects are broadly divided in two main categories, freeze-intolerance (-susceptibility) and freeze-tolerance. Freeze-intolerant insects are killed by freezing and, for winter survival, rely on a (stabilized) supercooled state at which the temperature of crystallization of body fluids (supercooling point, SCP) is depressed, usually to about $-25^{\circ} \mathrm{C}$ but sometimes much lower (about $-50^{\circ} \mathrm{C}$ ) in species/populations which are evolutionarily adapted to extreme conditions. Freezetolerant species are able to survive formation of extracellular ice (with some exceptions of non-lethal intracellular freezing). A striking characteristic of most freeze-tolerant insects is their relatively high SCP ranging typically from -6 to $-10^{\circ} \mathrm{C}$ (for recent reviews on insect cold hardiness see Lee \& Denlinger, 1991; Bale, 1996; Block, 1996; Danks, 1996; Sømme, 1999; Sinclair, 1999). It is now broadly accepted that the division of cold hardiness strategies to two main categories, although correct, does not fully describe the diversity of ecological relations and physiological mechanisms (Bale, 1993; Danks, 1996). Each of the two categories was subdivided into a few more or less distinct classes based on the relationship between the temperature of crystallization and the limits of cold survival (Bale, 1996; Sinclair, 1999).

The cold hardiness strategy of the gall midge Aphidoletes aphidimyza Rondani (Diptera: Cecidomyiidae) is investigated in this paper. A. aphidimyza is a polyvoltine species with a facultative overwintering diapause. Larvae are predators and are commercially used to control aphids in greenhouses (Adams \& Prokopy, 1980; Havelka, 1980, 1982). Mature larvae of the last instar drop down from plants, build cocoons in the upper layer of soil and pupate inside. The last larval instars and cocooned larvae are sensitive to photoperiod and under short day-lengths the cocooned larvae stop developing and enter diapause (Havelka, 1980; Havelka \& Zemek, 1988). We show in this paper that the diapausing larvae may survive exposure to subzero temperatures either in a supercooled or frozen state depending on the moisture conditions in their microhabitat. Ecological relevance of such a duality is discussed and an attempt is made to reconcile it with the existing dichotomic categorization of cold hardiness strategies (Bale, 1993, 1996; Sinclair, 1999).

\section{MATERIAL AND METHODS}

The larvae of $A$. aphidimyza from a laboratory population originating from a field population collected during summer 1995 in a colony of Myzus persicae (Sulzer) on Prumus persica (L.) at Palamós near Barcelona, Spain $\left(42^{\circ} \mathrm{N}, 3^{\circ} \mathrm{E}\right)$ were used for experiments in 1996/1997. The insects were reared according to the standard methodology published elsewhere (Havelka \& Zemek, 1988). To obtain cocoons with diapausing larvae, the insects were maintained under short-day (SD) conditions (10L : 14D) and a constant temperature of $17^{\circ} \mathrm{C}$. Mature larvae produced cocoons in a $2-3 \mathrm{~cm}$ layer of fine quartz sand. Newly formed cocoons were collected on day 25 after oviposition and were considered to be at day 0 of their diapause. On the same day (day 0) the cocoons were transferred to continuous darkness (DD) and a constant temperature of $3^{\circ} \mathrm{C}$ where they were stored for 20 or 60 days before they were used for experiments. During storage, high RH (close to $100 \%$ ) was assured by placing the cocoons over wet sterilized sand in plastic bags.

The temperature of crystallization of body fluids (supercooling point, SCP) was measured in whole, intact diapause cocoons by the method of Brunnhofer et al. (1991) at a cooling rate of $1^{\circ} \mathrm{C} / \mathrm{min}$. The specimens were taken out of the apparatus when their temperature decreased again to the level of SCP after the transitional warming up during crystallization and were stored at $\mathrm{DD} / 3^{\circ} \mathrm{C}$ until day 120 (to allow diapause to be terminated). The cocoons were then transferred into long-day (LD) conditions (18L : 6D), a constant temperature of $22^{\circ} \mathrm{C}$ and high RH (close to $100 \%$ ) where the adults emerged. Successful adult emergence was taken as a criterion of survival.

In order to verify if the cocoons are penetrable by ice crystals and if freezing of body fluids can be induced in A. aphidimyza larvae at relatively high subzero temperatures by surrounding ice, 24 cocoons were placed into the apparatus which allows the SCPs of a group of specimens to be measured simultaneously (for full description of the method and apparatus see Nedvěd et al., 1995). Each cocoon was in direct contact with a piece of wet 


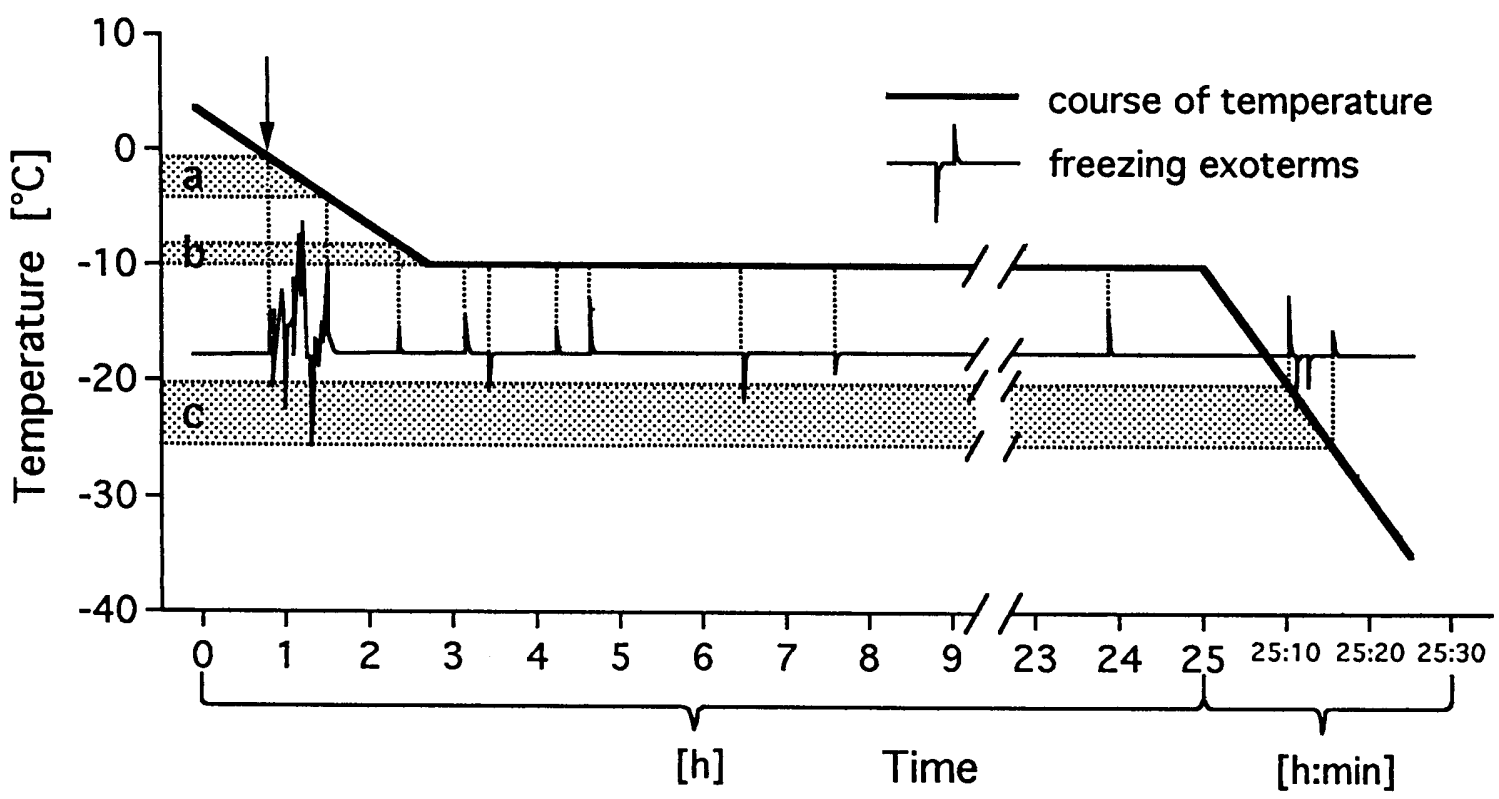

Fig. 1. The course of temperature decrease during the cooling protocol is depicted by the thick line. In the first step, the sample (twenty-four 60-day old diapausing larvae of Aphidoletes aphidimyza mounted individually to wet pieces of cellulose) was cooled from $3^{\circ} \mathrm{C}$ to $-10^{\circ} \mathrm{C}$ (cooling rate $0.08^{\circ} \mathrm{C} / \mathrm{min}$ ); in the second step, the temperature of $-10^{\circ} \mathrm{C}$ was maintained constant; and in the final step, the sample was further cooled to $-35^{\circ} \mathrm{C}\left(1^{\circ} \mathrm{C} / \mathrm{min}\right)$. The thin line represents a record of freezing events visible as individual, more or less separated, freezing exoterms (the actual temperature corresponding to each freezing exoterm must be derived from the thick line). The ice crystals were added to individual cocoons when the temperature reached $-1{ }^{\circ} \mathrm{C}$ (arrow). The wet pieces of cellulose and some larvae froze at temperatures between -1 and $-5^{\circ} \mathrm{C}$ (stippled area a); some larvae froze at temperature close to or of $-10^{\circ} \mathrm{C}$ (stippled area b); the remaining larvae froze during final cooling, at temperatures typical for spontaneous SCP (stippled area c). Note that the scale of the $x$ axis changes after $25 \mathrm{~h}$.

cellulose. The sample was cooled gradually from a starting temperature of $3^{\circ} \mathrm{C}$ at a slow rate of $0.08^{\circ} \mathrm{C} / \mathrm{min}$ (cooling head Polystat 44 coupled with control unit PD 415, Huber, Germany). When the temperature reached $-1^{\circ} \mathrm{C}$, a small ice crystal was added to each specimen to induce freezing. At $-10^{\circ} \mathrm{C}$, the cooling was stopped and the temperature was maintained at that level for a subsequent $22 \mathrm{~h}$. Then, the cooling was restarted (at a rate of $1{ }^{\circ} \mathrm{C} / \mathrm{min}$ ) and the sample was cooled down to $-35^{\circ} \mathrm{C}$. The example of the cooling protocol containing freezing exoterms is depicted on Fig. 1.

The exposure to $-10^{\circ} \mathrm{C}$ for 10 days was selected as a standard test of cold hardiness based on our preliminary experiments (Koštál, unpubl. results). Survival rates at (a) supercooled and (b) frozen states were tested in parallel samples of 100 diapausing larvae each: (a) cocoons were placed in plastic vials (5 $\mathrm{ml}$ ) lined with dry cellulose and the vials were placed in the freezer with temperature preset to $-10^{\circ} \mathrm{C}$; (b) cocoons were placed in plastic Petri dishes (diam. $5 \mathrm{~cm}$ ) lined with wet cellulose. The Petri dishes were cooled gradually from a starting temperature of $3^{\circ} \mathrm{C}$ at a slow rate of $0.08^{\circ} \mathrm{C} / \mathrm{min}$. When the temperature reached $-1^{\circ} \mathrm{C}$, a small ice crystal was added into the center of each Petri dish. At $-10^{\circ} \mathrm{C}$ the cooling was stopped and the Petri dishes were transferred into the freezer with temperature preset to $-10^{\circ} \mathrm{C}$. After the 10 -day-exposure, the (a) vials or (b) Petri dishes were transferred to $3^{\circ} \mathrm{C}$. The cocoons were allowed to recover/thaw for one day, returned to the storage conditions $\left(\mathrm{DD} / 3^{\circ} \mathrm{C}\right)$ and checked for adult emergence (as described above) on day 120 . Survival rate in a control (nonexposed) group of 500 cocoons stored for 120 days at $\mathrm{DD} / 3^{\circ} \mathrm{C}$ was taken for comparison.

\section{RESULTS}

Supercooling points of intact cocoons containing diapausing larvae of $A$. aphidimyza ranged from -19.0 to $-26.4^{\circ} \mathrm{C}$. Storage at $\mathrm{DD} / 3^{\circ} \mathrm{C}$ for 20 or 60 days had no influence on the SCP value (Table 1). None of the specimens that had frozen during SCP measurement survived to adult emergence. Our methodology did not allow to decide if the larvae died during/soon after freezing (acute injury) or later, during storage at $\mathrm{DD} / 3^{\circ} \mathrm{C}$ (latent injury).

Fig. 1 represents an example of the cooling protocol used to verify if the cocoons are penetrated by ice crystals and if freezing may be inoculated in larvae by external ice. Some of the larvae froze shortly after addition of an ice crystal at temperatures between -1 and $-5^{\circ} \mathrm{C}$ (Fig. 1, stippled area a); the exact numbers of frozen larvae could not be directly obtained from the record because the freezing exoterms were densely packed and mixed with the exoterms produced by freezing of wet pieces of cellulose. Some other larvae froze later, when temperature was close to or maintained constantly at $-10^{\circ} \mathrm{C}$ for $22 \mathrm{~h}$ (Fig. 1, stippled area b); the larvae could be easily identified by their isolated exoterms. Remaining larvae froze during the final cooling from -10 to $-35^{\circ} \mathrm{C}$ (Fig. 1, stippled area c); those larvae froze at temperatures typical for intact cocoons. None of the 24 larvae were able to remain supercooled (nonfrozen) at the end of our cooling protocol because the final temperature of $-35^{\circ} \mathrm{C}$ was substantially lower than the lowest SCP.

TABLE 1. Temperature of crystallization of body fluids (supercooling point, SCP) in diapausing larvae of Aphidoletes aphidimyza.

\begin{tabular}{lcccc}
\hline \multirow{2}{*}{$\begin{array}{l}\text { Age of diapause } \\
\text { larvae (days) }\end{array}$} & \multicolumn{4}{c}{$\mathrm{SCP}\left({ }^{\circ} \mathrm{C}\right)$} \\
\cline { 2 - 5 } & Mean & S.D. & range & $n$ \\
\hline 0 & -23.2 & 1.97 & -19.5 to -26.4 & $(10)$ \\
20 & -22.2 & 1.61 & -19.0 to -24.3 & $(10)$ \\
60 & -22.7 & 1.66 & -20.3 to -25.7 & $(10)$ \\
\hline
\end{tabular}


Table 2. Freezing of the diapausing larvae of Aphidoletes aphidimyza inoculated by external ice.

\begin{tabular}{|c|c|c|c|c|}
\hline \multirow{3}{*}{$\begin{array}{l}\text { Age of dia- } \\
\text { pause larvae } \\
\text { (days) }\end{array}$} & \multicolumn{4}{|c|}{ Numbers (n) of larvae frozen at temperature* } \\
\hline & -1 to $-10^{\circ} \mathrm{C}$ & $-10^{\circ} \mathrm{C} / 22 \mathrm{~h}$ & & 10 to $-35^{\circ} \mathrm{C}$ \\
\hline & $\mathrm{n}$ & $\mathrm{n}$ & $\mathrm{n}$ & $\mathrm{SCP} * *$ \\
\hline 0 & 14 & 8 & 2 & $-22.6 ;-25.9$ \\
\hline 20 & 9 & 11 & 4 & $-22.4 \pm 0.28$ \\
\hline 60 & 5 & 15 & 4 & $-23.0 \pm 1.18$ \\
\hline
\end{tabular}

* The three (ranges of) temperatures correspond to the three steps of cooling protocol which is described in Materials and Methods and an example is depicted in Fig. 1.

**B Both values or mean \pm S.D.

It means that we were able to calculate the numbers of larvae frozen immediately after the addition of an ice crystal (a) by subtracting the numbers of the larvae frozen later $(b+c)$ from the total number of larvae in the sample $(n=24)$. The exact numbers of larvae (of three different ages) frozen at different steps of cooling protocol $(\mathrm{a}, \mathrm{b}, \mathrm{c})$ are presented in Table 2 .

About $20 \%$ of $A$. aphidimyza larvae that were at the onset of their diapause before transfer to storage conditions $\left(\mathrm{DD} / 3^{\circ} \mathrm{C}\right)$, were able to survive exposure to $-10^{\circ} \mathrm{C}$ for 10 days either in a supercooled or frozen state. Survival rate increased to $87 \%$ in the supercooled specimens that were stored at $\mathrm{DD} / 3^{\circ} \mathrm{C}$ for 60 days. An increase of survival rate (to $34 \%$ ) during storage was indicated also in the frozen specimens but was less apparent (Table 3).

\section{DISCUSSION}

The diapausing larvae of $A$. aphidimyza were found to have relatively low spontaneous temperature of crystallization (SCP) ranging from -19.0 to $-26.4^{\circ} \mathrm{C}$. None of the specimens that had frozen at their SCP survived to adult emergence but high capacity for survival was found in supercooled larvae after 10 days at $-10^{\circ} \mathrm{C}$. Such features are characteristic for freeze- intolerance strategy, more specifically "chill tolerance" (sensu Bale, 1993, 1996). However, the cocoons formed by diapausing larvae were found to be penetrable by external ice crystals which inoculated freezing of larval body fluids. Twenty to sixty percent of cocoons were penetrated shortly after the addition of external ice, $30-60 \%$ were penetrated after a certain time-delay (minutes to hours) and some (8-17\%) were not penetrated at all during our test which lasted for about $25 \mathrm{~h}$. Thus, it seems that at least some cocoons may protect the diapausing larvae from inoculation by external ice for a limited time (roughly corresponding to one cold night, for instance) but most of them will be penetrated by external ice within one day. The diapausing larvae showed a relatively high survival $(23-34 \%)$ at $-10^{\circ} \mathrm{C}$ for 10 days in the frozen state caused by inoculation by external ice at a high subzero temperatures.

Such a duality with respect to cold hardiness strategy, although observed under laboratory conditions, seems to be ecologically relevant to the overwintering microhabitat of $A$. aphidimyza. The larvae are very small (fresh weight about 0.4 $\mathrm{mg}$ ) and have limited/no capability of active selection of the overwintering site in the soil. Although subzero temperatures are rather exceptional, they may transiently occur during winter even in the coastal parts of the Mediterranean region (Blondel \& Aronson, 1999), from where our laboratory population originated. Earlier results revealed that diapausing cocoons of $A$. aphidimyza are prone to rapid desiccation which results in high mortality. For instance a decrease of RH from $100 \%$ to $70 \%$ caused $100 \%$ mortality of diapausing larvae (Havelka, 1980). It
TABLe 3. Survival of the diapausing larvae of Aphidoletes aphidimyza after exposure to $-10^{\circ} \mathrm{C}$ for 10 days in either supercooled or frozen state.

\begin{tabular}{lcc}
\hline \multirow{2}{*}{$\begin{array}{c}\text { Age of diapause larvae } \\
\text { (days) }\end{array}$} & \multicolumn{2}{c}{ Survival rate $(\%)^{*}$} \\
\cline { 2 - 3 } & $\begin{array}{c}\text { supercooled } \\
\text { larvae }(n=100)\end{array}$ & $\begin{array}{c}\text { frozen } \\
\text { larvae }(n=100)\end{array}$ \\
\hline 0 & 20 & 23 \\
20 & 69 & 27 \\
60 & 87 & 34 \\
\hline
\end{tabular}

* Successful adult emergence was taken as a criterion of survival. Survival rates were checked after the larvae reached day 120 of their diapause. Survival rate in the control, nonexposed, group $(n=500)$ stored at $\mathrm{DD} / 3^{\circ} \mathrm{C}$ for 120 days was $76.3 \%$.

is clear that $A$. aphidimyza larvae have a greater chance to survive winter in a moist soil. Thus, ice crystals, which are abundantly formed when the temperature falls below zero in a moist soil, may inoculate overwintering cocoons and cause their freezing as was shown in this study.

Similar duality of cold hardiness strategy has been previously described in a few other insects which overwinter in wet habitats: adult carabid beetle Pelophila borealis (Østby \& Sømme, 1972; Sømme, 1974) and prepupa of the fly Sciara sp. (Tanno, 1977) overwinter in litter or soil; adult tenebrionid beetle Bolitophagus reticulatus overwinters inside the tinderfungi on trunks of dead beeches (Gehrken et al., 1991). The mature larvae of a drosophilid fly, Chymomyza costata overwintering under bark of fallen trees, showed the SCP around $-20^{\circ} \mathrm{C}$ and spontaneous freezing at this temperature caused mortality; thus they were categorized as freeze-intolerant (Enomoto, 1981). Later experiments, however, revealed that these larvae can survive extremely low temperatures in a frozen state (even $-196^{\circ} \mathrm{C}$ in liquid nitrogen), provided they were appropriately cold acclimated, the freezing was inoculated by external ice at relatively high temperatures about $-2^{\circ} \mathrm{C}$, and the cooling rate was slow (Shimada \& Riihimaa, 1988, 1990; Moon et al., 1996). In addition, larvae of the alpine beetle Pytho deplanatus, overwintering under bark of fallen trees, were found to have an extremely low SCP of $-54^{\circ} \mathrm{C}$, however, they survived subsequent cooling down to $-55^{\circ} \mathrm{C}$ (Ring, 1981). A growing list of insect species/populations, that are alternatively freeze-intolerant or freeze-tolerant depending on the actual moisture conditions in their microhabitat, suggests that such a duality may be common in insects overwintering in soil or under bark of fallen trees where contact with external ice is unpredictable both over temporal (daily and seasonal fluctuations) and spatial (different microhabitats) scales.

The duality of cold hardiness strategy described in this study and in some earlier papers (see above) seems to differ from the situation found in larvae of beetles Dendroides canadensis and Cucujus clavipes (Horwath \& Duman, 1984; Duman, 1984). In the northern Indiana populations of these beetles, the "switch" from a freeze-tolerant to a freeze-intolerant strategy was observed between two overwintering seasons. In contrast to the insects with a dual response, the larvae of $D$. canadensis or $C$. clavipes (a) accumulated INA in their haemolymph when freeze-tolerant, while (b) did not accumulate INA and could not survive freezing when inoculated by ice at relatively high temperatures when freeze-intolerant.

Clearly, whilst the cold hardiness strategies, as complex mechanisms used by overwintering insects, may be classified in two main "distinct, parallel and therefore alternative" categories (i.e. freeze-tolerance and -intolerance) (Sinclair, 1999), 
overwintering insects (or populations) do not "obey" this dichotomy and may be categorized as: (1) using just one of the two strategies, (2) capable of using both strategies alternatively (e.g. A aphidimyza and other examples in this paper) or (3) switching between the two strategies from season to season (e.g. D. canadensis and C. clavipes).

ACKNOWLEDGEMENTS. We thank $O$. Nedvěd and I. Hodek (Institute of Entomology AS CR, České Budějovice) for discussions and valuable comments on the manuscript. The study was supported by a grant from the Grant Agency of the Czech Republic (grant no. 522-98-0228).

\section{REFERENCES}

AdAms R.G. \& Prokopy R.J. 1980: Aphidoletes aphidimyza (Rondani) (Diptera: Cecidomyiidae): an effective predator of the apple aphid (Homoptera: Aphididae) in Massachusetts. Prot. Ecol. 2: 27-39.

BALE J.S. 1993: Classes of insect cold hardiness. Funct. Ecol. 7: 751-753.

BALE J.S. 1996: Insect cold hardiness: A matter of life and death. Eur. J. Entomol. 93 : 369- 382.

BLOCK W. 1996: Cold or drought - the lesser of two evils for terrestrial arthropods? Eur. J. Entomol. 93: 325-339.

Blondel J. \& Aronson J. 1999: Biology and Wildlife of the Mediterranean Region. Oxford University Press, Oxford, New York, $328 \mathrm{pp}$.

BrunNhofer V., NedVĚd O. \& HodKová M. 1991: Methodical improvement for measuring of supercooling point in insects. Acta Entomol. Bohemoslov. 88: 349-350.

DANKS H.V. 1996: The wider integration of studies on insect cold-hardiness. Eur. J. Entomol. 93: 383-403.

DUMAN J.G. 1984: Change in overwintering mechanism of the cucujid beetle, Cucujus clavipes. J. Insect Physiol. 30: 235-239.

Eломото O. 1981: Larval diapause in Chymomyza costata (Diptera: Drosophilidae) II. Frost avoidance. Low Temp. Sci. (B) 39: $31-39$.

Gehrken U., Strømme A., Lundhem R. \& Zachariassen K.E. 1991: Inoculative freezing in overwintering tenebrionid beetle, Bolitophagus reticulatus Panz. J. Insect Physiol. 37: 683-687.

HAVELKA J. 1980: Some aspects of photoperiodism of the aphidophagous gallmidge Aphidoletes aphidimyza Rond. Bull. IOBC/WPRS 3: 75-82.
Havelka J. 1982: A predatory gall-midge Aphidoletes aphidimyza (Rondani) (Diptera, Cecidomyiidae) - a method of mass laboratory rearing, and use in the biological control of aphids on greenhouse plants. In: Proc. Symp. IOBC/EPRS. Institut ochr. rostlin, Poznań, pp. 89-121 (in Russian).

HAVELKA J. \& ZEMEK R. 1988: Intraspecific variability of aphidophagous gall midge Aphidoletes aphidimyza (Rondani) (Dipt., Cecidomyiidae) and its importance for biological control of aphids. J. Appl. Entomol. 105: 280-288.

HoRwath K.L. \& DuMAN J.G. 1984: Yearly variations in the overwintering mechanisms of the cold-hardy beetle Dendroides canadensis. Physiol. Zool. 57: 40-45.

LeE R.E. JR. \& DENLINGER D.L. (eds) 1991: Insects at Low Temperature. Chapman and Hall, New York and London, 513 pp.

MoON I., FuJIKaWA S. \& SHIMADA K. 1996: Cryopreservation of Chymomyza costata larvae (Diptera: Drosophilidae) at $-196^{\circ} \mathrm{C}$ with extracellular freezing. Cryo-Letters 17: $105-110$.

Nedvĕd O. Hodková M., Brunnhofer V. \& Hodek I. 1995: Simultaneous measurement of low temperature survival and supercooling in a sample of insects. Cryo-Letters 16: 108-113.

Østby E. \& SøMme L. 1972: The overwintering of Pelophila borealis Payk. I. Survival rates and cold-hardiness. Norsk. Entomol. Tidskr. 19: 165-168.

RING R.A. 1981: The physiology and biochemistry of cold tolerance in Arctic insects. J. Therm. Biol. 6: 219-229.

SHIMADA K. \& RImIMAA A. 1988: Cold acclimation, inoculative freezing and slow cooling: Essential factors contributing to the freezing-tolerance in diapausing larvae of Chymomyza costata (Diptera: Drosophilidae). Cryo-Letters 9: 5-10.

Shimada K. \& RilHimaA A. 1990: Cold-induced freezing tolerance in diapausing and non-diapausing larvae of Chymomyza costata (Diptera: Drosophilidae) with accumulation of trehalose and proline. Cryo-Letters 11: 243-250.

SinCLATR B.J. 1999: Insect cold tolerance: How many kinds of frozen? Eur. J. Entomol. 96: 157-164.

SøMme L. 1974: The overwintering of Pelophila borealis Payk. III. Freezing tolerance. Norsk. Entomol. Tidskr. 21: 131-134.

Sømme L. 1999: The physiology of cold hardiness in terrestrial arthropods. Eur. J. Entomol. 96: 1-10.

TANNO K. 1977: Ecological observations and frost-resistance in overwintering prepupae, Sciara sp. (Sciaridae). Low Temp. Sci. (B) 35: 63-74.

Received January 10, 2000; accepted March 20, 2000 